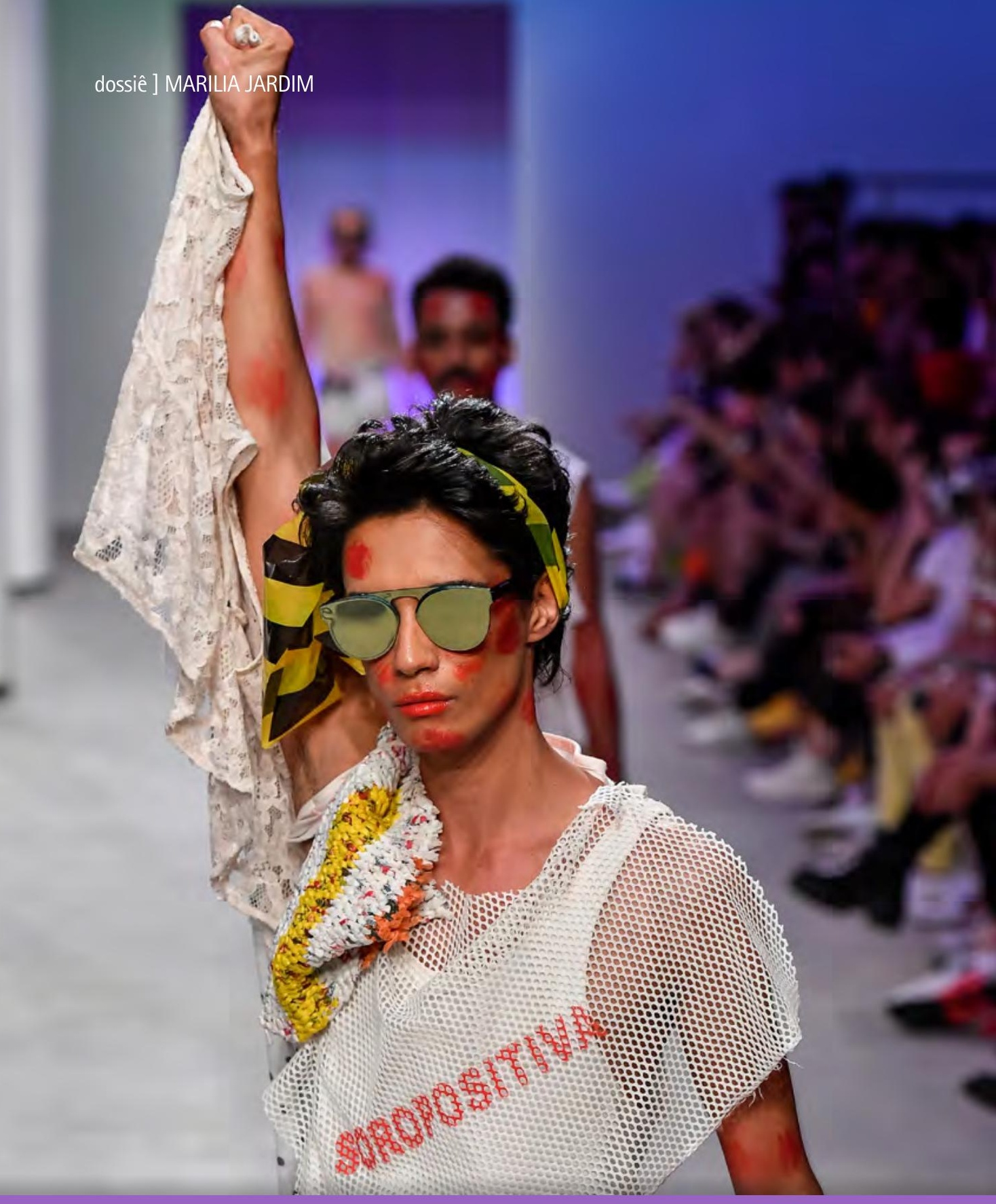

\title{
The corset and the veil as disruptive manifestations of clothing: the tightlacer and the Tuareg
}

0 corset e o véu enquanto manifestações disruptivas do vestuário: a tightlacer e o Tuareg 


\section{[MARILIA JARDIM]}

Mestre em Comunicação e Semiótica. Pesquisadora independente e professora de Contextual and Critical Studies na University for the Creative Arts (UK)

E-mail: mhernandesjardim@uca.ac.uk

[abstract] This work investigates two items of clothing and the relations constructed between their fashionable and disruptive manifestations: the Corset and the Veil. Examining the societies which are emblematic of those practices - the Victorian Era and the Tuareg, from Northern Africa - the works of Greimas and Landowski will provide a framework for a Semiotic and Socio-semiotic analysis of the practices of tightlacing and male veiling as opposing practices to traditional gender roles. Even though the two practices forming the corpus of this work are geographically and chronologically distant, our analysis forms a parallel between them, exposing how the mechanism of Otherness through clothing occurs similarly at different times and locations, as well as the importance of Fashion in creating and sustaining prevalent ideologies.

\section{[keywords]}

\section{corset; veil; tightlacing; Tuareg;} semiotics.

[resumo] 0 presente trabalho investiga dois itens de vestuário e as diferentes relações construídas entre suas manifestações alinhadas com a moda, ou rompendo com seu sistema: o corset e o véu. Examinando as sociedades das quais estas práticas são emblemáticas - a Era Vitoriana e os Tuaregs do norte da África - os trabalhos de Greimas e Landowski serão utilizados enquanto base teórica para uma análise semiótica e sociossemiótica das práticas do tightlacing e do uso masculino do véu muçulmano enquanto oposição aos papéis de gênero tradicionais. Ainda que as práticas discutidas neste trabalho sejam geográfica e cronologicamente distantes, nossa análise forma um paralelo expondo em que medida os mecanismos de alteridade criados por meio da vestimenta ocorrem de maneira similar em diferentes periodos e locais, e igualmente a importância da Moda na produção e no suporte de ideologias predominantes.

[palavras-chave] corset; véu; tightlacing; Tuareg; semiótica. 
Throughout its history, Fashion has proven to serve two main distinctive roles: the one of reproducing prevalent ideologies or forms of social order and, at the same time, the one of challenging and rejecting what is established, proposing change. As such, every new Fashion can be interpreted as a disruptive manifestation in which, to introduce the new, the old must be challenged, deemed as outdated and backward so that it can make room for the new. However, not all disruptive manifestation becomes a new Fashion, in the sense of a widespread embodiment of a manner: some disruptions remain as cluster practices belonging to a small group, while other disruptions may become the fashion of one society, but be perceived as something else outside of that particular cultural milieu.

The present work will closely examine two manifestations of this type, which sprout from established sartorial practices in a given society, resorting to the same garments, but completely subverting its meanings: the corset and the veil. Looking firstly at the extreme tightlacer in the Victorian Era, by comparing the excesses of corseting versus the "fashionable" form of body modification, we will attempt at understanding how the same object can manifest both the conformation to an established social order and ideal feminine role, or the complete destruction of that role and social order. Secondly, we will look at the Tuareg custom of male veiling, which is opposed to the Muslim tradition where, when veiling is practised, it appears as covering the heads and faces of women. Such reversal is normally interpreted by those seeing their culture from the outside as a possible "gender reversal," which on its turn is perceived as a rejection of a masculine social role or of patriarchal privilege.

The analysis proposed must resort to the context in which those two garments are apprehended as "disruptive" - meaning that we are discussing the "normal" corset use versus the "excessive" use from a Victorian perspective, as well as understanding the "strangeness" of Tuareg veiling as seen from an Islamo-Arab perspective. The disruptive character of the objects, thus, doesn't belong to the object enclosed in itself, but to the different relations which can be established through the different dress practices. That includes the understanding that tightlacing exists "after" the invention of corsets for "regular lacing;" and that Tuaregs are, likewise, part of a larger community of Muslims, which gives Islamo-Arabic societies the possibility of understanding their custom of veiling as deviant from a fundamentalist ${ }^{1}$ interpretation of the Qur'an. In other words, what we are here naming a "disruptive manifestation of fashion" is the non-conformity to the established practices, which happen through the use of the same object: what makes the disruption, in our corpus, is a change in the manner in which the object is used. Those different practices are responsible, from the point of view of the culture where those objects originated, for a degeneration of the objects in rebellion, perversion, anti-fashion - in other words, for the construction of a relation of Otherness. 
The investigation presented here is focused on reflecting theoretically about the case, rather than offering an enclosed case study. Our analysis resorts to the scope of Standard Semiotics and the Semiotics of Interactions, anchoring our study in the notion of thematic role (GREIMAS; COURTÉS, 1993), and how the two sartorial objects - the corset and the veil - originate as means of reinforcing those thematic roles, by supporting the wearer in performing their own thematic role. When it comes to an understanding of the disruption of such roles, we will examine how the thematic role can be conforming to an established social structure, producing programmed interactions (LANDOWSKI, 2005), or how it can degenerate in accidents (LANDOWSKI, 2005), producing manifestations which constitute a disjunction between the narrative path of the individual and society. The result of the analysis led to Landowski's works about taste presented in Passions sans nom (2004), which permitted the unfolding of our category in terms of sociability or intimacy associated with the different uses or practices of the objects in discussion.

Another concept we borrow from the analysis of the text is the idea of actantial engagement (embrayage actantiel) (GREIMAS; COURTÉS, 1993) which, although belonging to the domain of written discourse, can serve the purpose of analysing any manifestation which can be read in terms of enunciation and enunciate. We understand that dress is one type of manifestation which approximates the concepts of enunciation and enunciate, considering it produces acts of communication as much as written text, and therefore the link between the two fields appears as pertinent. Our aim is to study dress in a manner which is not grounded in Visual Semiotics, as is usually the case whenever a work aims at using Semiotics as a method to analyse Fashion and Dress: we understand that the plastic is not the only significant dimension of this particular object and that other concepts appearing in Semiotics can produce enriching discussions and analysis.

One of the key aspects concerning the two objects selected to compose our corpus of analysis is the matter of identity vs alterity - an old friend of Structural Semiotics. The forms of self-presentation resulting from the uses and practices of corsets and veils are also closely linked to a problem of distortion of meaning, which was pointed by Barthes (2009) as the operation through which myth hijacks and bends signification. Following those definitions, it is possible to state that perhaps the main element uniting the Tightlacer and the Tuareg is the manner in which the presentation of their bodies creates mythical identities, both in the sense that their practices are distortions of "crystallised" identities, and when it comes to the interpretations those practices suffer outside of their cultural milieu. 
It is essential to remark we understand the delicate place in which this investigation is located: the one which turns the Othered subject into an object of research. Even though the attempt at further looking into those practices carry the aim of understanding prevalent misunderstandings, to speak of the Other is, more often than not, to support the mechanisms producing Otherness in the first place. Trapped in a dilemma of which of two evils is worse - to comply with the invisibilities and misconceptions, or to reinforce the "exotic"? - we chose to attempt at addressing the Other as a subject, as well as accepting the noise those practices create in the mainstream culture as important places of struggle and challenge of the established norms.

\section{The tightlacer}

We continuously perceive the "us" and the "others" through a series of oppositions, and dress is certainly an important part in this intricate process of recognition of the insiders - the ones who belong to our group; and outsiders - the ones who do not conform to the established, and sometimes unspoken rules of presentation of the self. According to Kunzle, what delimits the "ins" and "outs" of the Fashion system are normally intimately intertwined with the dominance of a social class (KUNZLE, 2004) - undoubtedly a statement derived from Veblen's thinking (2007) - but the same could also emerge from concepts presented by Baudelaire, such as a form of "circumstantial beauty," or even as the "obsession of an era" (BAUDELAIRE, 1964). Or, to follow Greimas, the rhythm of Fashion, which includes not only the sartorial practices, progresses following or preceding the rhythm of the generations (GREIMAS, 2002). For Barthes, finally, what is fashionable is nothing less than "[...] health, it is a moral code of which the unfashionable is nothing but illness or perversion" (BARTHES, 2006, p. 68).

When it comes to marking relations of affiliation and membership through dress, it is easy to see how "foreign" dress can easily be identified as a badge of Otherness. However, it is not rare the dress of the Other - or, what we are here calling a disruptive manifestation of dress - appears within the same society, the same system of values, as a "perversion" of a practice already existing in the predominant form of dress. It is undoubtedly the case of the tightlacer or the one who "perverts" the use of the corset through the exaggeration of its function and action over the body.

Tightlacing, a term without equivalent in other languages, is the name given to the practice of lacing corsets very tightly, with the objective of dramatically reducing the size of the waist. A gradual, but permanent (and perhaps irreversible) process, tightlacing is a form of body modification requiring training and discipline, which includes wearing corsets every 
day, and sometimes all day (even during sleeping hours). With the years of practice, the body slowly starts to accommodate the smaller waist size and to reorganise itself around the new shape, which includes repositioning of the organs and bones, increase in the shape of the spine, and changes in the texture of other body tissue. Although the descriptions in this paragraph frequently appear in popular culture as a reference to all corset use in the past, it is important to stress that many authors agree that tightlacing was never a "widespread" practice, and is far from being the norm at any given period (KUNZLE, 2004; LYNN, 2010; STEELE, 1997, 2001).

For Kunzle, Fashion and Fetishism must be regarded as antagonists, especially when the fetish in question relates to an exaggeration of what is fashionably accepted (KUNZLE, 2004). Therefore, what produces Otherness in the practice of tightlacing is not the use of the corset perse, which is, essentially, the same corset used by other women in the Victorian era. What separates both, thus, is the quality of the use or practice: in one case, the modification created in the body is according to the fashionable limits, whereas in the other case, the modification surpasses those limits. At this point, it is imperative to affirm that what separates "normal lacing" from tightlacing is not the assumption that the first one is not sexualised: even if "The history of tight-lacing is part of the history of the struggle for sexual self-expression [...]" (KUNZLE, 2004, p. 38), the primary function of the silhouette created by corsets and crinolines is one of enhancing the sexual characteristics of the female human body (JARDIM, 2014). The compression of the waist - even when practised within the fashionable limits - produces the illusion of broader hips and broader chest, both intimately associated with the reproductive function of the female body, communicating the ability to get pregnant, bare children, and give birth.

Therefore, if tightlacing is intimately connected to sexual self-expression, it is not the sexualisation of the body which constituted the "illness or perversion" of a practice, but the matter of disrupting a thematic role relating to a particular form of sexuality. Following Greimas and Courtés, the thematic role relates to the determination of a position in the path of an actor, which permits a precise isotopy to be fixed to their role (GREIMAS; COURTÉS, 1993, p. 393). In other words, it is a repetition of a theme, in which there is very little room for "personal self-expression." When it comes to dress and, more specifically, to the corset, it could be argued that the thematic role of the corset is to support the body in the fulfilment of its own thematic role which, on its turn, will ensure the individual fulfils their own thematic role. In the context of the societies in which the use of the corset was the norm for women, the sexual enhancements it creates in the female figure relate to a thematic role that finds its roots perhaps in religion, but existing to serve a clear social function: the one of generating heirs. 
To what extent, thus, surpassing the established fashionable limits of body modification degenerates into illness and perversion? To answer such question, it is crucial to examine broader thematic roles - not only the ones governing the actions of individuals (e.g. men and women in the Victorian era) but the ones dictating the global relations established between countries and their peoples. Hence, to speak of Victorian England is necessarily to speak of the focal point of a large empire, one very attached to the ideas of its own civilisation and superiority, regarded necessarily as different from the subject races they conquered. Therefore, it is not an exaggeration to say that the thematic role of Victorian England was one of dominance and progress or, at the least, that was the thematic role the Victorians felt to be their own.

Tightlacing, different from its fashionable counterpart, is a form of body modification which tends towards permanence (KUNZLE, 2004) - while, to evoke timeless statements, "[...] fashion is characterized by change" (STEELE, 2005, p. 12). Thus, before anything else, tightlacing can already be defined as an anti-fashion practice due to its tendency of lasting, challenging the expected change and progress which characterises Fashion, an idea connected to the core of a Western mentality of constant development. Besides denying the thematic role of "natural" sexuality one focusing the bearing of children and a life of dedication to the home ${ }^{2}$ - the practice of tightlacing also attacks the thematic role of Fashion, which is one of producing successive changes in the dress, but also in the body. Corset-wise, in three centuries of its use in the West, it is possible to see the development of the feminine silhouette from a more triangular shape in the 16th to mid-18th century, to a more cylinder-like shape in the late-18th century, to a round, hourglass or wasp-shape in the mid-19th century, all the way to the straight front corset of the 1900's (cf. LYNN, 2010; STEELE, 2001). Notwithstanding, due to the nature of tightlacing, not only the de-formation of the body is to a certain extent irreversible, but the body becomes incapable of following the different shapes which may subsequently become a new vogue, becoming forever trapped in the same form, which can only develop into more exaggerated variations throughout the years of practice.

In addition, permanent body modifications are also commonly associated with "primitive customs" of non-Western cultures (KUNZLE, 2004), many of which can be found among the peoples who are, for the British, their "subject races": tattooing and foot binding, popular in China at the time; body piercing, a mark of "Indian-ness"; or the many forms of skin scarification, practiced among the native peoples of Africa and Oceania. Furthermore, Kunzle and Steele identify tightlacing not as an affluent phenomenon, but a "minority cult", practised mainly by lower- and mid- 
dle-class women (KUNZLE, 2004; STEELE, 2001). When regarded from this angle, the practice of tightlacing can be read as an affront not only to individual thematic roles, but to the thematic role of the collective, through the engagement with a practice that is closer to the ones of the "uncivilised" conquered nations, as well as to the lower classes, than to the ones of the "superior," "advanced," and distinctive, dominant Westerners. By crossing a very fine line which distinguishes the fashionable from the unfashionable, the tightlacer manifests through her body and her corset a multi-layered opposition to the thematic role of Victorian women, which goes from the claiming of a sexuality that is freed from the mythical "succession of pregnancies", to rejecting all the forms of privilege attached to an English Victorian identity: the affiliation to a dominant class, the possibility of following Fashion, or the very status of "civilization".

Permanent body modification, thus, can be understood as a badge of Otherness in the West, in the sense that it tends to permanence and $d u$ ration, versus the prevalent idea of change as a mark of progress and development. Regarding the matter through the theory of aspectualisation (GREIMAS; COURTÉS, 1993, p. 21-22, 111, 270, 285, 389), Fashion belongs to the process of punctuality, which marks the beginning of a process, but also the absence of duration; a practice such as tightlacing, on the one other hand, not only produces bodies marked by terminativeness, or accomplished bodies when it comes to the goal of permanent modification, but it presupposes durativity: a body doesn't become modified overnight, requiring years of disciplined training to achieve a visible alteration of shape. One cycle of Fashion is surely not enough time to accomplish tightlacing goals, which means the practice is not compatible with Fashion's punctuality, producing bodies which become inevitably "outdated".

Secondly, the irreversibility of tightlacing approximates the ones who practice it to the "true" Others, the ones geographically and chronologically distant. Such closeness between the perverted and healthy side of a practice can be the explanation to the passion with which many different subjects in Victorian society fought tightlacing. It was associated with atheism, with "race suicide", with infanticide and abortion, with masturbation, and, following the late 19th century obsession with racial purity, accused to be both cause and symptom of the degeneration of the Anglo-Saxon race; If all that was not sufficient, tight-lacing was also considered to be linked with excess of vanity, excess of work, and excess of study - all of which was perceived by the conservatives as incompatible with the place of women in society (Kunzle, 2004). Finally, Kunzle points that the fiercest opposers of tight-lacing as a practice were the most misogynist defenders of the ideal of the "natural woman," who should be dedicated to the home, to house chores, and to children (KUNZLE, 2004, and also STEELE, 1997), a 
statement which confirms our relation established between the moderate use of the corset and a thematic role of maternity.

In his analysis of taste, Landowski constructs a category that separates objects in cosmetics: items and substances serving to adorn the body, transforming its figure with the aim of pleasing the other; and narcotics: acting over the objectal dimension of the body and opposing interaction, producing bodies that are intoxicated with themselves (LANDOWS$\mathrm{KI}, 2004)$. While cosmetics generate sociability and interaction - even if, paradoxically, they turn the body into an object for the gaze of the other - narcotics produce the opposite of communication: they are for lonely enjoyment, focusing on the relation with one's own body. Observing the practice of tightlacing through this category can provide clues about the extent to which the moral investments play a strong role in one and another form of using (or practising) the corset. The presupposed use reveals a cosmetic role of the corset as an object embellishing the body and constructing a desirable figure, related to fulfilling a role of procreating for/ with another; the tightlacing, however, even if not a sexual perversion or a form of "masturbation," is at least a form of obsession with the own body, regardless of the perception of the other. As such, the corset ceases to play a part in constructing a body-for-the-other, constructing a body-for-theself instead: the accomplishment of a waist reduction is a goal in itself, and one that intoxicates the body (both physically, through the reduction of the breathing capacity; and psychologically, through the accomplishment of a goal, or vanity, or fetishist sexual arousal).

Hence, there is a moral line separating the fashionable use of the corset from its anti-fashion counterpart: the same that separates the cosmetic use of substances as an enhancer of sociability, or the use creating addicts, who isolate themselves from society to fully surrender to the excess of pleasures - and even that can be subjected to Fashion. Finally, Landowski remarks that in the relation with the narcotics, body and substance become one, through a mutual assimilation which culminates in the subject annihilating themselves in the object (LANDOWSKI, 2004): the tight-laced body becomes tightlacing, the corset becomes the body, and the body becomes the corset - two instances that can no longer be separated.

The objective of this item has been the one to expose how the rejection of tight-lacing happening in every society in which it was practised confirms our analysis, which places the practice as an anti-thematic role institution in several different manners. Notwithstanding, such is also the way in which a mythical identity of the tightlacer was able to be born in the first place. Perhaps, the manner in which popular imagination presumes that all women from "the past" were tightlacers is our manner of 
reaffirming the idea that tightlacing is a retrograde, backward practice, which is associated with the past (permanence) and not with the future, with progress, with advancement (fashion, or change). Even today, fetishism and corsets are associated either with a "vintage" aura - romantic almost, but still "freaky" and "repelling" - or with a "futuristic" feel which is both dystopian and dysphoric: a degenerated future. The uneasiness associated with the body of the tightlacer is deeply grounded in the disruption of thematic roles we are, as a society, used to, but also to the disruption of what is human in a body, transcending the limits of a fashionable figure.

Ultimately, it is possible to identify the fear of the opposers of tight-lacing with a fear of elimination and destruction, which is at the foundations of the fear of the Other, embodying both the unknown and the familiar - and here we could evoke both Said, when he claims the Orient is feared because it is so close and so similar to the West (SAID, 2003), or even Freud, the Unheimlich defined as what was once familiar but became unfamiliar (FREUD, 2010). Such possibilities will help to take us to the next step in the analysis.

\section{The Tuareg}

It could be concluded that the identity constructed through the extreme lacing of corsets is a mythical one, and that the strangeness of the practice, as well as the results it produces when permanently modifying the body, are directly related to the possibility of creating relations of Otherness. For Žižek, following Lacan's ideas, the Other is linked to the unknown and to what one cannot understand (ŽIŽEK, 2012). The narratives created for the big Other, in Žižek's writings, are closely linked to the presence of veiled faces in Western society, and the Westerners' repulse for the niqab appears related to the manner in which it causes the suspension of facial recognition and facial expression, which is at the base of social interaction in Western culture (ŽIŽEK, 2011).

The discomfort with a veiled face, however, is not exclusive to the West. In Islamo-Arab societies likewise, although the veiling of a woman's face is naturalised, the veiling of a man's face can be seen as out of place, and to produce confrontations to multiple thematic roles in the same fashion as the tightlacer. It is certainly the case of the Tuareg, as they are known in Western vocabulary: a nomad Muslim people from Algeria, Libya, Mali, and Niger, which are known for their fierceness as warriors and their music, but mainly for their "intriguing" custom involving the veiling of their men (instead of their women).

As remarked by Jean Sebastian Lecocq, the Tuareg would rank very high in an imaginary list of the most mythical peoples (LECOCO, 2010). 
Named by the French les guerriers des sables ${ }^{4}$ (LECOCO, 2010) and les hommes bleus ${ }^{5}$ - which refers both to their emblematic traditional dress of indigo robes, turbans and veils, and also to the manner in which the rubbing of the clothes stains their hands and feet (MURPHY, 1964), their image was used, in the West, to illustrate a broad range of concepts, from the Muslim rebel in the desert to the selling of off-road $4 \times 4 \mathrm{~s}$. As much as it was possible for Victorian society to make the tightlacer responsible for all evils, the same complexity and strangeness of Tuareg custom in dress permits the coining of an identity embracing all the extremes, both to the West and to their Islamo-Arab neighbours, who seem to find their customs equally curious, deviant of their tradition and religion.

Authors who studied the nomad peoples of the Sahara seem to agree that the veil is by far the most potent symbol of "Tuaregness" (KEENAN, 2004), as a great deal of analysis was dedicated to the attempts at understanding the "meaning" of the veil among Tuareg men (KEENAN, 2004; LECOCO, 2010; MURPHY, 1964). What is of special interest to the present work is that the misunderstanding, followed by a mixture of curiosity, fascination, and repulse surrounding the sartorial practices of the Tuareg men seem to unite the West and the Arab world. Although the image described in the previous paragraph is undoubtedly an orientalist one - to evoke the meanings Said creates for the word (SAID, 2003) - it is important to clarify that the relations of Otherness created around the Tuareg remit back to before the colonial conquests (KEENAN, 2004; LECOCO, 2010). On the one hand, even if the adherence to Islam unites the Tuareg and the Arab peoples, the animist form of maraboutic Islam practised by peoples of the Sahara is very distant from the fundamentalist interpretation of the Qur'an practiced in the Arab world (KEENAN, 2004); Murphy remarks, for example, that even though Tuaregs are Muslims, they are perceived to be, in Islamo-Arab eyes, as "[...] infamous and unregenerate back-sliders who observe neither proper law nor custom [...]" (MURPHY, 1964, p. 1262).

Although many earlier works about the Tuaregs attempted at providing many explanations for the use of their veil, some of them aiming at presenting a utilitarian reason relating to protecting the face from the sun, the wind, and sand (cf. DUVEYRIER, 1864), the three authors selected to support our present investigation agree when it comes to the fragility of such theories, chiefly because they fail to explain why only men would wear the veil, and also why its use would be extended to all the hours of the day, including the moments in which men are alone or asleep indoors (KEENAN, 2004; LECOCO, 2010; MURPHY, 1964). With such debates in view, we opted for dismissing the possibility of a functional account of the veil among the Tuareg, focusing on the social functions presented by the same authors as prevalent in their anthropological investigations among tribes from different geographical locations. 
Our analysis of the tight-lacers' situation concluded that the relations of Otherness are closely related to an opposition of progress vs permanence, which couldn't be more accurate to the case of the Tuaregs. In many ways, their culture is perceived as something "from the past" for both the West, the Arab world, and the surrounding African societies. Furthermore, and again similarly to the tightlacers, the Tuareg occupy a place in between, at least when it comes to their relation to the Arab world: not geographically distant and, to a certain extent, with cultural practices which meet at their roots, and yet lost in an archaic version of the religion and culture. To summarise, the core aspects in which the veil is "interpreted" by the surrounding cultures (sedentary African, Islamo-Arabic and Western societies) relate to the alleged relation between the veil and matrilineal societies, or a "reversal" of gender thematic roles among the Tuareg; and the ambivalent role the veil assumes in social interactions.

The matter of matrilineality among the Tuaregs divides authors, especially due to the difficulty in creating a clear-cut category in which every Tuareg group would fit in (LECOCO, 2010). The most informed analysis on the matter seems to come from Robert F. Murphy, who states that the relations of rank and class among Tuareg groups are defined through both patrilineal and matrilineal ties (MURPHY, 1964). Even if a complete opposition with the West and Islamo-Arab societies is not formed in the matter, it is relevant to remark that Islam is a religion associated with the emergence of a patriarchal social order: in Women and the Advent of Islam, Leila Ahmed highlights how the many aspects of the revelation seemed to serve the transition from a matriarchal model of society and lineality to a patriarchal and patrilineal organisation (AHMED, 1986). Among those aspects, polygamy and the seclusion of the women - both the seclusion de facto and the symbolic seclusion, manifested in the veil - are probably the most visible indicators of a patrilineal organisation, in which the certainty of biological paternity is crucial, culminating in a substantial reduction of feminine sexual freedom. Such relates, on its turn, to the close relation between passing on a state to the heirs, and the idea of social position as spatial occupation. From a patriarchal, if not Islamic point of view ${ }^{6}$, the thematic role of men would more or less universally surround the elements mentioned above: control over women, the occupation of space through possession, and the possibility of passing on a state to heirs.

When attempting at understanding why nomadic customs seem so incomprehensible to sedentary societies, Lecocq concludes the matter emerges from the renunciation of spatial occupation (LECOCQ, 2010). In the absence of spatial ownership which marks nomadic societies, the positions are not defined by what is owned, but by to whom you are related to (KEENAN, 2004; LECOCO, 2010; MURPHY, 1964), a social order which is 
compatible with both patrilineal and matrilineal organisations. Again, the renunciation to this primordial part of a masculine thematic role can be interpreted as the opposition to the masculine thematic role itself which, visually, is manifested through a difference in sartorial custom: the men who accept the thematic role (in Islamo-Arabic societies, for example) do not veil, but their women do; whereas the men who reject the thematic role (the Tuareg) veil their faces, and their women do not.

Face the overlapping of the reversal in the veiling custom - when compared to Islamo-Arabic societies - and the mix of matrilineal and patrilineal relations of class and rank, it is easy to reconstruct the path to concluding that the veiling of men can be interpreted as a different condition of women in that society as well, when compared to other Islamic societies. In fact, Tuareg society seems to allow a higher freedom in the interactions between the genders (LECOCO, 2010; MURPHY, 1964); the main miscomprehension, however, is to believe that, opposed to fundamentalist Islam, the veil is there to mark the seclusion of men: again, considering the absence of spatial occupation and possession in Tuareg society, the weight of biological paternity is reduced, when compared to traditionally sedentary and patriarchal societies, making seclusion not relevant.

Among the many meanings associated with the male veil, Keenan reaches an intriguing conclusion in his work: for the author, the veil is used mainly as an ambivalent tool to both facilitate and protect the individual from the dangers of social interaction (KEENAN, 2004). This conclusion is primarily drawn from the writings of Murphy, who presents a detailed analysis of the relation between the custom of veiling and the protection of the mouth and the area surrounding the eyes, which are the most expressive features of the face, the ones which allow interacting subjects to read thoughts and feelings the most (MURPHY, 1964). The role of the veil could then be to both disguise and to show: through the obliteration of facial expressions which could denounce uneasiness or manifest contradictions between words and thoughts/feelings, the veil permits a safe presence in social interactions, which is marked by the absence of the individual (the recognisable facial expression), who is replaced by the role he plays in the group.

The resulting effect of emptying the individual from subjectivity, to privilege the presentation of a social role, relates to the procedure of actantial engagement (embrayage actantiel) in written text, appearing in Standard Semiotics: in place of erasing the marks of the enunciate to then project non-persons in the enunciate, the engaged discourse suspends the oppositions of person, time, and space, proposing a return to the enunciation (GREIMAS; COURTÉS, 1993, p. 119-121). For José Luiz Fiorin, in 
the engaged discourse amplified persons can mean singular persons and vice-versa, as well as the non-person (the projections in discourse resulting from the procedure of disengagement (débrayage)) can signal persons (FIORIN, 2016). In written text, or in the "live" interactions - which we accept, in this paper, to constitute enunciations in act - the instances of "I/here/now" are the ones which anchor the text as enunciate, as a product rather than an act. The engagement, on the other hand, proposes a return to the enunciation, destabilising the referential character, unveiling the referential illusion. Hence, the veil can be interpreted as destabilising many different referential aspects, from facial recognition to the reading of expressions, to the separation between individual and social role.

Finally, engagement can be understood as the denial of the "non-I" the "I" projected in the discourse - by the "I" subject of enunciation, which aims at the impossible return to the source of enunciation (GREIMAS; COURTÉS, 1993, p. 120). In the written text, the actantial engagement manifests an ideal, the erasure of the marks of the enunciate, proposing a return to the act of communication; in that sense, it is possible to interpret the mechanism as one of treachery: the engagement is what gives the reader one person in the place of another, or multiple persons who can count as one, or one person who can count as multiple. By doing so with what we identify more closely to an "identity" - the biometrical identity, facial recognition, and the facial expressions which frequently accompany the conversational communication - the Tuareg veil gives a social role in the place of the individual, but one can count for the other, the opposition between them suspended. In the written text, the engagement aims at disguising the enunciate, whereas the veil, in the face-to-face interaction, aims at disguising the marks of individuality. More than relating to the Tuareg fame among Westerners and the Arabs of disguising their faces for deceptive purposes (KEENAN, 2004), the idea of the face veil as actantial engagement remits back to a set of fears relating to veiled figures, mainly the ones that what is seen may not correspond to what is underneath - that what we perceive visually as a woman can be a male terrorist in disguise, for example, especially in the West.

Different from the tightlacer, the use of the veil generates ambivalent meanings, depending on the point of view adopted in the analysis. At a first glance, and continuing the conversation about narcotics and cosmetics, it could be argued that the role of the veil is a cosmetic one, as it relates to the maintenance of appropriate social relations: the veil works protecting the individual to enable the accomplishment of his social role. However, with the prolonged use in mind, the Tuareg veil's relation to the body of the wearer approximates the one created between the corset and the tightlacer, in which veil and man too become one, mutually appropri- 
ated, inseparable even during meal time, sleep, and even the sexual act. As such, even when in social interaction, the subject's experience is always mediated by the object which is omnipresent, literally creating a barrier to sociability - even if that barrier is, contradictorily, what enables sociability.

An ambivalent manifestation in itself, the veil is the perfect case to present the discourse surrounding a group which, in our analysis, can be homologated to the contradictory figure of the Tuareg man. The alleged matrilineality, the relative gender freedom of their society, the social fragility exposed by the need of protection during social intercourse, all construct a value of "in between", which, on its turn, can be unravelled in a few more oppositions: future vs past, dominant vs dominated, I vs Other. In a very similar fashion to the tightlacer, the Tuareg veil appears as a practice which dances between extremes, constructing relations of Otherness through practices which can be understood as misappropriating or exceeding [détournement, dépassement], to follow Landowski's (2009) terms. Similarly to the tightlacer, the veil of the Tuareg also responds to more than one set of meanings within the cultural milieu in which it appeared, as well as outside. In both cases, the garments construct relations of Otherness through the denial and rejection of established thematic roles, but also precisely because the meaning one group attributes to the garment doesn't match the meaning attributed by the groups surrounding it, or looking at that particular culture from the outside.

In the case of the Tuareg specifically, the Otherness closely relates to the suspension of facial expression, which can be more "disturbing" than the deformed body of the tightlacer: the idea of mystery, the possibility of treachery or the suspension to the "right to see" can stimulate the imagination much more than what is explicitly manifest, gaugeable by the eye. However, for both European and Islamo-Arab societies, the strangeness goes beyond that, sprouting perhaps from the idea of a gender reversal, which can be read, at the fundamental level, as a rejection of the patriarchal privilege; such is also linked to the nomadic way of life, which dismisses the occupation of space, the most disseminated form of expressing patriarchal domination and social position. Secondly, even if the social meaning of the veil remained unknown among the first anthropological attempts during colonial periods, the manner in which the veil is used to disguise facial expression as a form of social protection also confronts the classical patriarchal idea of man as consistently strong and fearless, the one who protects and not the one who needs protection.

The analysis presented in this item certainly does not cover the multitude of issues concerning the Tuareg veil and its relation to Otherness. However, with the aim of constructing a parallel with the Victorian Era's 
extreme tightlacer, we opted for focusing on the emblematic elements which provided the occasion of proving that those two garments, the corset and the veil, can be analysed together, as they were shown to form isotopies which persist, regardless of geographical and chronological distance.

\section{Conclusion}

The present work aimed at analysing two manifestations which, although geographically, chronologically, and culturally distant from each other, seem to produce similar effects of Otherness within the cultural milieu surrounding them. Throughout our analyses, it was made evident that both manifestations share the same popular anecdotes which identify the Other in a society, which relate to the misunderstanding of their practices - in the present case, sartorial practices - and how those are reinterpreted and connected to the "evils" associated with social decay.

In both cases, the confrontations to the sartorial practices seem to relate to the rejection of a traditional thematic role: in the case of the tightlacer, the traditional feminine sexuality, which should focus on the home and procreation; in the case of the Tuareg, the veil comes connected to an alleged matrilineality, which links to the rejection of a masculine thematic role, one of domination and power over women, space, and possessions. Following that logic, the tightlacer becomes the abortionist, the pervert or fetishist, the infanticide, and the one contributing to the "degeneration of the Saxon race" for the Victorians (KUNZLE, 2004; STEELE, 1997); whereas the Tuareg become the ones who cover their faces because they are ugly (KEENAN, 2004), or because they are treacherous, bad Muslims who observe no proper law or custom (KEENAN, 2004; MURPHY, 1964). The type of Otherness created can be summarised in an inability to conform to the established codes for women and men in a given society, which results in the identification of such practices with what is outside (Other) rather than inside (us) that particular society.

When it comes to the actual items of dress in discussion, however, the possibility of comparing those two garments as isotope - may Jean-Marie Floch rest assured we are not here comparing locomotives and racoons (FLOCH, 1990, p. 29) - reside in the ambivalence created around the piece of clothing, which assumes a contradictory role in the social interaction. For Kunzle and Steele, the evening corset must be the tightest, because it is at night that sexual insinuations are permitted, but also when the body needs to be guarded the most (KUNZLE, 2004; STEELE, 1997) - the corset becomes, thus, what shows and what disguises, revealing the sexually insinuating silhouette, but also armouring the body against unwanted advances: perhaps another presentation of the mechanism of engagement 
(embrayage) we identified with the veil. For Keenan and Murphy, the veil covering the mouth and the area around the eyes functions as a tool safeguarding facial expression, disrupting the possibility of reading involuntary reflexes of the face which can give away thoughts and feelings (KEENAN, 2004; MURPHY, 1964) - the veil becomes, equally, what shows and what disguises, erasing the marks of the subject and enabling him to engage in social interaction not as an individual, but as a social role. Both garments seem to function through mechanisms relating to the complex term, rather than belonging to one or another term of the opposition.

The analysis showed that both items of dress are governed by a category of change vs permanence, in which the Other is customarily associated with permanence, which is reinterpreted as "backwardness" - while, to evoke the writings of so many theorists of Fashion, change is perceived as a value relating to evolution and development, hence the euphoric feelings still associated with it in the West and in countries aiming at belonging to a Western logic of civilisation. In the case of permanent body modification, the corset approximates the practices of the Others perceived as "subject races" in the Victorian Era, denying the possibility of following Fashion: the body becomes eternally trapped in the shape of the corset. The Tuareg, likewise, are normally associated with an "outdated" version of Islam which, as we exposed, relates more to pre-Islamic practices than those of the fundamentalist Islam practised in the Arabised societies, and the same goes for their nomadic customs, which are still perceived as something which came "before" sedentary societies. From that point of view, it is important to remark that Arab culture is also invested with imperial aspirations, and the rejection of "properly Islamic" practices, the ones relating to a patriarchal masculine role, are also oppositions to the thematic role of an empire, similarly to what the tightlacer does by rejecting her role as part of a dominant culture, identifying with practices belonging to the Others, the "uncivilised" subject races.

The answer to our initial question, about how the same garment can produce belonging and Otherness, seems to locate in the matter of the transformation of the object's meaning in the same cultural tradition. Both the corset and the veil, in the contexts of the Victorian Era or fundamentalist Islam, are garments associated with women, and the fulfilling of a patriarchal feminine role. In the Western Victorian era, the corset is the piece that covers the body of the woman, shaping it into an ideal form, which is one manifesting values of fertility, sexual availability, and the competence to procreate. In Islam, the veil is the piece that covers the head and the face of the woman, manifesting her symbolic seclusion, signalling her unavailability to other men. The tightlacer and the Tuareg both subvert those thematic roles - both the garment's and the subject's - through the use of the same sartorial objects to fulfil different, de-formed functions. 
Although it was not our initial objective to study the subcontraries resulting from this opposition, it is possible to imagine the manners in which our base category of change vs permanence can unfold in transitional terms (figure 1). Each term of our initial opposition possesses two manifestations, one relating to British/Western culture, the other to Islamic culture. The first, relating to change and Fashion, is the one manifesting the conformity to established systems and manners, both Fashion and the religious/cultural codes which are subject to change, following the development of societies. The manifestations of permanence, on the other hand, can appear both in anti-fashion practices (which more often than not look at the past, or practices outside of the cultural milieu) and by religious diaspora, which are both linked to "anti-progress" attitudes, but also with confronting or anti-conformism towards newly established practices. Both sides of this opposition constitute traditional, and thus crystallised systems, even if they are subject to change.

Figura 1: Articulation of the category Change vs Permanence.

Crystallised Systems

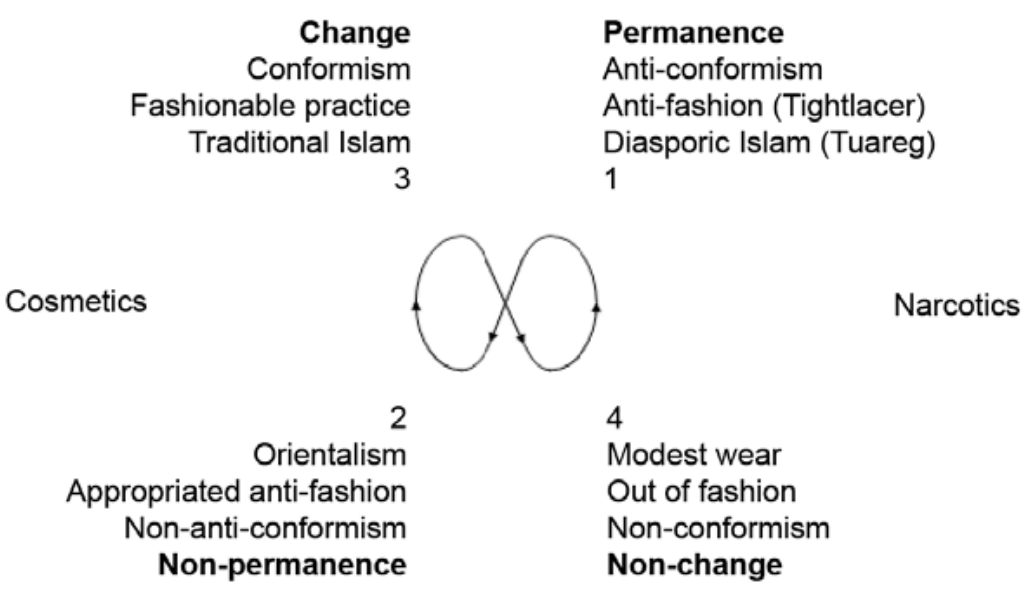

Updated Systems

Source: elaborated by the author (2018).

The terms leading from one and the other relate to what leads the path from anti to fashionable, or from conformity to anti-conformism, positions which are strongly entangled with the destiny of Fashion and Culture. Starting with anti-fashion - after all, we are here to discuss disruptive manifestation of Fashion - the appropriation of countercultural dress and behaviour by the mainstream system is well known in Fashion Theory, and is the mechanism through which what used to be unacceptable can become "a classic". The negotiation of elements from anti-fashion to fashion 
manifests a form of non-permanence, transforming anti-conformists in non-anti-conformists, in which the permanence is appropriated and used as a substance for a new trend, which can then be assimilated and become a new consolidated fashion. The gradual reduction of the waist from the 16th to the early 20th century (LYNN, 2010) can serve here as evidence that, at least to an extent, tightlacing "inspired" the fashionable use of the corset, pushing the boundaries of the appropriateness and the acceptable to accommodate smaller waists which, slowly, became mainstreamed - but also pushing the "real" tightlacers to become even more extreme since, as remarked by Melissa Richards, "Anti-fashion is [...] the opposite of fashion, so if it exists, it should be different every time fashion changes" (RICHARDS, 1999, p. 146). As for the veil, Orientalism is a strong element of Fashion, both for the Western and Arab worlds, which are ironically entangled in trends that promiscuously mix cultural manifestations, with no regard for previous meanings invested in objects and practices. In Landowski's ellipse of the regimes of taste, this position is identified with the seductor or the pleaser, the one seeking sociability even if that costs their pleasure (LANDOWSKI, 2004, p. 267): perhaps a discerning definition of what contemporary mainstream fashion has become. In both cases, the meaning behind the cultural practices is lost, emptied to accommodate the fashionable.

The opposing subcontrary position inverts this relation, presenting us with the "pleasure seeker", the one living for the taste of pleasure, even if at the cost of the sociability (LANDOWSKI, 2004, p. 267). A position relating to the same "taste for pleasures" that marks the narcotic relations between body and object, it could be manifested in the practices that blend fashionable/culturally accepted behaviours to their narcotic versions. In this term, we see the purposeful "out of fashion" that accommodates the comfort or the pleasure of the wearer, or the mixing of fashionable and religious codes which, again, serve the enjoyment of the clothed subject. What separates this type of outcast from the seductor/manipulator is the absence of a desire to please or to belong to the mainstream (or to the anti-cultural) system, which is replaced by a form of "personal cult" of the objects. The bottom axis formed by the subcontraries presents updated systems which are not yet crystallised but serving as points of transition in which either new fashions and cultural customs, or new forms of rebellion and counter-culture are cultivated.

It is possible, thus, to propose a new category, one of certainty vs ambivalence, which could be what separates Fashion from the disruptive manifestations of dress that may occur with the same item of clothing, but depending on the manner in which this item is worn. Fashion, to recap the words of Barthes, is a manifestation of what is correct and healthy, and 
even when its discourse is monstrous or grotesque, the relations constructed by Fashion belong to the realm of certainty: in or out. On the one other hand, whatever is out - of Fashion, of custom, of propriety - can have many shapes, many reasons, many meanings. The dis-ease in dress, the unhealthy, the out, the old, the kitsch, the vulgar, the camp - the dysphoria of what is outside of the custom is, thus, related to ambivalent meanings and its many possibilities. Perhaps the source of Otherness exists precisely in the complex place in which the reading of the codes is confused, and a clear message is no longer possible.

Hence, the production of Otherness through dress can be summarised in the suspension of the certainty of the thematic roles, which is replaced by a complex manifestation - belonging to the regime of the accident, to use the concept proposed by Landowski (2005) - which doesn't provide clear borders like the traditional thematic roles do. The Other, thus, becomes the one who doesn't yield certain codes, limits, and messages, destabilising the social structures and challenging the established roles, manners, and formations. Proving once more the critical role of dress in defining social interactions, but also as a manner of reading society, clothes become a major social actor, capable of manifesting both terms of this category, as well as both possibilities contained in the two items of dress and their practices presented in this paper: the complete con-formation to the rules and conventions of society, or its destruction.

\section{Recebido: 15-10-2018}

Aprovado: 13-02-2019

${ }^{1}$ The term here used to its literal meaning, a literal or strict interpretation of the scriptures, rather than the current derogatory used by Western media.

2 Besides exploring such ideas in depth in my work about the corset (cf. JARDIM, 2014), authors such as Anthony Giddens (1993) and Michel Foucault (2012, 2012a) provide extensive insight supporting the arguments made in this section.

${ }^{3}$ The veil that covers the face, leaving only a small slit for the eyes, worn by a small minority of Muslim women in the West

4 "The warriors of the sands" in free translation.

5 "The blue men".

${ }^{6}$ Although the Qur'an is replenished with references to possessions and the proper manner for men to divide them among their wives, sons, daughters, and other relatives, which appear throughout the text (cf. ABDEL HALEEM, 2011).
} 


\section{REFERENCES}

ABDEL HALEEM, M. A. S. The Qur'an. A new translation by M. A. S. Abdel Haleem. Oxford: Oxford University Press, 2011.

AHMED, Leila. Women and the advent of Islam. Signs. Chicago, v. 11, n. 4, p. 665-691, Summer 1986.

BARTHES, Roland. The Language of Fashion. Oxford: Berg, 2006.

BARTHES, Roland. Mythologies. London:Vintage, 2009.

BAUDELAIRE, Charles. The Painter of Modern Life and Other Essays. London: Phaidon, 1964.

DUVEYRIER, Henri. Les Touareg Du Nord. Exploration du Sahara. Paris: Challamel Aîné, 1864.

FIORIN, José Luiz. À propos des concepts de débrayage et d'embrayage: les rapports entre la sémiotique et la linguistique. Actes Sémiotiques, Limoges, n. 119, February 2016. Available at: http://epublications.unilim.fr/revues/as/5605 Accessed in: 10 $0^{\text {th }}$ March 2019.

FLOCH, Jean-Marie. Sémiotique, marketing et communication. Sous les signes, les stratégies. Paris: PUF, 1990

FOUCAULT, Michel. História da Sexualidade. A vontade de saber. São Paulo: Graal, 2012. v. 1.

FOUCAULT, Michel. História da Sexualidade. 0 uso dos prazeres. São Paulo: Graal, 2012a. v. 2.

FREUD, Sigmund. 0 Inquietante. Obras Completas. São Paulo: Companhia das Letras, 2010. p. 329376. v. 14.

GIDDENS, Anthony. The Transformation in the Intimacy. Sexuality, Love \&t Eroticism in Modern Societies. Cambridge: Polity Press, 1993.

GREIMAS, Algirdas Julien. Da imperfeição. São Paulo: Hacker, 2002.

GREIMAS, Algirdas Julien; COURTÉS, Joseph. Dictionnaire raisonné de la théorie du langage. Paris: Hachette, 1993.

JARDIM, Marilia. 0 Corset na Moda Ocidental. 2014. Dissertação (Mestrado em Comunicação e Semiótica) - Programa de Pós-Graduação em Comunicação e Semiótica, Pontificia Universidade Católica de São Paulo, São Paulo, 2014.

KEENAN, Jeremy. The Lesser Gods of the Sahara. Social Changes and Contested Terrain amongst the Tuareg of Algeria. London and Portland: Frank Cass, 2004.

KUNZLE, David. Fashion and Fetishism. Corsets, tight-lacing \& other forms of body-sculpture. Stroud: Sutton, 2004.

LANDOWSKI, Eric. Passions sans nom. Paris: PUF, 2004.

LANDOWSKI, Eric. Les interactions risquées. Limoges: PULIM, 2005.

LANDOWSKI, Eric. Avoir prise, donner prise. Actes Sémiotiques, Limoges, n. 112, 2009. Available at: http://epublications.unilim.fr/revues/as/2852. Accessed in: 10 ${ }^{\text {th }}$ March 2019.

LECOCQ, Jean Sebastian. Disputed Desert. Decolonisation, Competing Nationalisms and Tuareg Rebellions in Northern Mali. Leiden, Boston: Brill, 2010.

LYNN, Eleri. Underwear Fashion in Detail. London: VEtA, 2010.

MURPHY, Robert F. Social distance and the veil. American Anthropologist, Arlington, v. 66, n. 6, Part 1, p. 1257-1274, December 1964.

RICHARDS, Melissa. Anti-fashion and Punk Couture. Key Moments in Fashion. London: Hamlyn, 1999. p. 144-155.

SAID, Edward. Orientalism. London: Penguin, 2003. 
dossiê ] MARILIA JARDIM

STEELE, Valerie. Fetish: fashion, sex and power. New York, Oxford: Oxford University Press, 1997. STEELE, Valerie. The Corset. A Cultural History. New Haven and London: Yale University Press, 2001. STEELE, Valerie. Fashion. in: STEELE, Valerie. Encyclopedia of Clothing and Fashion vol 2. New York: Scribner/Thomson, 2005. p. 12-13.

VEBLEN, Thorstein. The theory of the leisure class. Oxford: Oxford University Press, 2007.

ŽIŽEK, Slavoj. Living in the End Times. London: Verso, 2011.

ŽIŽEK, Slavoj. The Year of Dreaming Dangerously. London: Verso, 2012. 